\title{
UN ENFOQUE A LA IMPORTANCIA DEL TURISMO
}

\author{
AN APPROACH TO THE IMPORTANCE OF TOURISM
}

Ema Carmen Julca Meza

Universidad de San Martín de Porres

\section{RESUMEN}

La Organización Mundial del Turismo (OMT), define al turismo como la suma de relaciones y de servicios; el turismo crea las interrelaciones de importancia social, pero crea principalmente las interrelaciones económicas, así, este se ha convertido en el motor del quehacer turístico y en una de las actividades económicas más importante de varios países, en los cuales el turismo no solo impacta al propio sector económico, sino que además influye en los resultados de otros sectores, en la calidad de vida de los habitantes y su desarrollo social, al igual que en la conservación de los atractivos turísticos.

Palabras clave: OMT, turismo, desarrollo social, atractivos turísticos, servicios.

\begin{abstract}
UNWTO defines tourism as the sum of relationships and services; tourism creates the interrelationships of social significance, but mainly creates economic interrelationships, so this has become the engine of tourism work and one of the most important economic activities in several countries, in which the tourism not only impacts the own economic sector, but also influences the results of other sectors, the quality of life of the inhabitants and their social development and conservation attractions.
\end{abstract}

Keywords: UNWTO, tourism, social development, tourist attractions, services 


\section{Introducción}

La promoción turística es definida como «el conjunto de acciones para el desarrollo e incremento de las corrientes de visitantes efectuada tanto por instituciones privadas como públicas, respecto de estas últimas, se estaría hablando de ministerios o secretarías, departamentos, direcciones u oficinas de turismo» (Franco, 2003, p. 20).

En un contexto integrado por atractivos turísticos, promoción turística y profesionales de turismo, las acciones públicas y/o privadas, llevadas a cabo con el fin de incrementar el número de visitantes a un país, región o una determinada zona turística para posicionar dicha zona como destino turístico en los diversos mercados nacionales e internacionales, con el objeto de generar flujos turísticos hacia dicho territorio; es un rol importante asignado a la formación profesional en turismo.

\section{La necesidad de contar con colaboradores capacitados}

El turismo como disciplina ha crecido a lo largo del tiempo. Muchas universidades del mundo han ampliado el rango de materias ofrecidas con el estudio del turismo, tal es así, que durante la primera mitad del siglo XX, varias universidades europeas habían ya establecido cátedras de turismo. Inicialmente, los programas de gestión hotelera añadieron el turismo a sus currículos. Pronto, la capacitación en turismo comenzó a extenderse a otros programas y departamentos, gestión de negocios, ocio, esparcimiento, e incluso ciencias sociales.

La oferta actual va desde cursos aislados hasta concentraciones minoritarias o mayoritarias en turismo, tanto en el nivel de licenciatura como en el graduado. Significativamente, el número de universidades que ofrecen cursos avanzados está en aumento. Por varios años ya, algunas universidades en todo el mundo han extendido sus programas doctorales en educación, ocio y planificación urbana-regional para incluir el turismo y algunas ofrecen ya doctorados en turismo (Jafari, 2005).

La formación profesional en turismo en su acepción de formación para el trabajo, se relaciona con determinados segmentos de dicha actividad económica. Un primer segmento lo constituyen los trabajadores que ocupan los niveles más altos, que son los más propensos a capacitarse, pues tienen más acceso a la educación de calidad. Un segundo grupo corresponde a los niveles medio y bajo en donde la capacitación específica en áreas afines mejora la empleabilidad así como la calidad de las condiciones de vida.

\section{Turismo y empresa}

El turismo es celebrado como una decisiva fuerza económica global y una gigantesca industria mundial Jafari (2005). Muchas publicaciones de la Organización Mundial del Turismo (OMT), entre otras, dan buena cuenta de su estable crecimiento desde la Segunda Guerra Mundial. Por ejemplo, en 1950, 25.3 millones de turistas generaron US\$2.100 millones. A finales del siglo XX, en 1998, el número de turistas internacionales estaba ya en 625 millones que gastaron US\$ 445 millardos. Ese mismo año, el gasto mundial total por turismo internacional y doméstico superó los tres mil billones de dólares americanos. Esta última cifra, según algunos analistas, es varias veces mayor que el gasto mundial en defensa; o, dicho de otra manera, el gasto mundial 
en turismo excede el producto nacional de todos los países del mundo a excepción del de Estados Unidos y Japón. En 2015, el número de turistas internacionales fue de 1.184 millones de llegadas.

Las características económicas del turismo como actividad productiva (actividad intensiva en trabajo) y las nuevas situaciones derivadas de los cambios políticos y económicos a escala internacional, exigen prestar una especial atención a la relación entre empleados y productividad. Luego, la capacidad de los mismos para ajustarse a las nuevas exigencias, depende del nivel de formación. En este contexto, la formación de profesionales para el sector turismo debe detectar las necesidades y exigencias del mundo turístico, pero sin perder de vista los obstáculos para elaborar un sistema de formación que por lo general están centrados alrededor de las siguientes condiciones propias de la actividad (Sancho, 2008):

1. El crecimiento espontáneo de la actividad turística en la mayoría de los países.

2. La importante presencia de empresas de tamaño pequeño y mediano de explotación familiar.

3. La estacionalidad de la actividad turística.

4. El carácter de servicio personal de la mayoría de los trabajos realizados.

5. La variedad de servicios y actividades a realizar: Polivalencia.

6. La propia heterogeneidad del sector turístico.

7. La escasa atención que han dedicado tradicionalmente los gobiernos a la actividad turística.

Por el lado de la empresa, podemos observar cómo la formación profesional puede y debe ser un elemento esencial para la eficacia, productividad y competitividad, al elevar la calidad de los productos y su rendimiento, así como la adaptabilidad de los trabajadores a los cambios. Ante este escenario de transformaciones constantes, la formación profesional en turismo, en especial la basada en la competencia laboral, adquiere una importancia vital. La formación profesional también ha pasado por un proceso de cambios. Se inició centrada en la creación de conocimientos, habilidades y destrezas para la vinculación a un empleo. Actualmente, además de haber pasado de un concepto de formación inicial a uno de formación continua, ha ampliado su significado y alcances hacia aspectos como el desarrollo tecnológico y el complejo mundo de las relaciones laborales. (Ministerio de Trabajo y Promoción Social, s/f).

La formación de profesionales de turismo en el Perú, está orientada a la actividad de servicios y tiene como fin principal, la satisfacción de las nuevas demandas que exige la actividad turística. En razón de ello, el profesional de turismo se caracteriza por contar con las siguientes capacidades:

1. Gerenciar y administrar hoteles manejando instrumentos, criterios y conceptos aplicados a los servicios de recepción, pisos, restaurantes, bar, cocina, etc.

2. Planificar, organizar, dirigir y ejecutar diversos proyectos empresariales como son los eventos, ferias, congresos, convenciones, etc. 
3. Brindar asesoramiento en proyectos y estudios de inversión en el sector.

4. Gestionar y dirigir empresas turísticas, como agencias de viajes, líneas aéreas, casinos, pubs, cafés y otros.

\section{Conclusiones}

1. El análisis de mercados turísticos permite conocer de manera precisa las características del turista.

2. Facilita un mejor empleo de los recursos disponibles y da la oportunidad de mejorar el producto turístico para su venta. Ya que para atraer a un mercado, se requiere que el prestador de servicios conozca muy bien el producto turístico que está vendiendo, con el fin de determinar si puede satisfacer las necesidades de sus clientes.

3. La sociedad tiende cada vez más al incremento de la productividad, menor tiempo de trabajo, mayor tiempo libre y mayor deseo y motivación de integración con el mundo actual y pasado.

4. Dado que el Perú tiene el enorme privilegio de poseer recursos turísticos, sean estos naturales o culturales, en todas sus regiones, es posible encontrar más ventajas en proyectos turísticos, que en otros proyectos de distinto desarrollo económico.

5. El turismo permite vislumbrar perspectivas alentadoras para los países que impulsan su actividad turística, permitiendo diversificar la economía tradicional de los países.

\section{Bibliografía recomendada}

Aljovín de Losada, C. (edit.). (2002). La universidad en el Perú. Lima: UNMSM, Fondo Editorial.

Arrieta, F. (2003). Algunos Aportes y Fundamentos para el Desarrollo de la Docencia Universitaria en el Perú. Lima: Corporación Grafimundo.

Asamblea Nacional de Rectores (edit.) (2002). Una Nueva Universidad para una Nueva Sociedad. Lima:

ANR. Gurria, M. (2007). Introduccion al Turismo. México: Trillas.

Ramos, G. (2005). La Universidad Peruana en el Siglo XXI. Lima: Editorial Universitaria URP.

Sancho, A. (2008). Introducción al Turismo. Buenos Aires: Organización Mundial del Turismo. 